\title{
Teresa Chevrolet, L'idée de fable. Théories de la fiction poétique à la Renaissance
}

\section{Dario Cecchetti}

\section{Q OpenEdition \\ 1 Journals}

\section{Edizione digitale}

URL: http://journals.openedition.org/studifrancesi/8854

DOI: 10.4000/studifrancesi.8854

ISSN: 2421-5856

\section{Editore}

Rosenberg \& Sellier

\section{Edizione cartacea}

Data di pubblicazione: 1 octobre 2008

Paginazione: 439

ISSN: 0039-2944

\section{Notizia bibliografica digitale}

Dario Cecchetti, «Teresa Chevrolet, L'idée de fable. Théories de la fiction poétique à la Renaissance», Studi Francesi [Online], 155 (LII | II) | 2008, online dal 30 novembre 2015, consultato il 12 janvier 2021. URL: http://journals.openedition.org/studifrancesi/8854 ; DOI: https://doi.org/10.4000/studifrancesi.8854

Questo documento è stato generato automaticamente il 12 janvier 2021.

\section{(c) $(1) \&$}

Studi Francesi è distribuita con Licenza Creative Commons Attribuzione - Non commerciale - Non opere derivate 4.0 Internazionale. 


\title{
Teresa Chevrolet, L'idée de fable. Théories de la fiction poétique à la Renaissance
}

\author{
Dario Cecchetti
}

\section{NOTIZIA}

TERESA CHEVROLET, L'idée de fable. Théories de la fiction poétique à la Renaissance, Genève, Droz («Travaux d'Humanisme et Renaissance», n. CDXXIII), 2007, pp. 765.

1 In un momento in cui si moltiplicano interesse e lavori sulla riscrittura dei miti classici, giunge benvenuta la bella e monumentale thèse di Teresa Chevrolet sulla concezione della fabula e del suo ruolo nelle poetiche cinquecentesche. Se alla fine del Medioevo ci si accostava ancora alle favole poetiche seguendo la teoria esegetica del quadruplice senso, e si affermava la presenza di una verità profonda sub cortice fabularum (concezione, questa, su cui si fonderà la difesa umanistica della poesia), nel QuattroCinquecento a partire dal platonismo ficiniano si tratterà di confrontarsi con le posizioni di Platone - sempre negative - nei confronti della 'favola', vista dal filosofo antico senza eccezione come menzogna. Nel Cinquecento soprattutto «si tratterà, per molti teorici della poesia, di riflettere sulla natura stessa della menzogna poetica, modulandola, rivalorizzandola mediante l'analisi delle sue gradazioni: così un poeta 'allegorista' che narrasse con intenzione didattica dei racconti fittizi, sarebbe in qualche modo meno mentitore del poeta che riconoscesse di avere raccontato favole soltanto per produrre piacere e senza preoccuparsi di attribuire loro un senso morale. Vi sarebbero pertanto delle menzogne scusabili e delle menzogne inescusabili» (p. 23) e sarebbe l'infedeltà rispetto a Platone da parte dei teorici del neoplatonismo, che pur mostrando deferenza per il testo della Repubblica non esitano talvolta a inserire nel dettato che interpretano l'elogio delle finzioni allegoriche che li affascinano, a mantenere la favola al centro dei trattati di poetica. Sarebbe intorno a quest'affermazione del valore (e a questo permanere dell'uso) della favola nel 
Cinquecento che si coagulano le teorie rinascimentali della finzione poetica: in due direzioni, a seconda che la fabula sia vista, nella prospettiva dell'ermeneutica neoplatonica e dell'esegesi biblica tradizionale, come 'allegoria' (e sia pertanto portatrice di un sensus altior), oppure sia vista, sulla scorta della poetica aristotelica, come 'mimesi' (e sia pertanto il luogo del 'verosimile', spazio artificiale in cui si manifesta l'abilità del poeta a raffigurare il 'reale'). L'importante, interessante e utile lavoro di T. Chevrolet segue queste piste (fino alle teorizzazioni di fine Cinquecento, tra cui esemplare quella del Tasso che sfocerà in un superamento della dicotomia fra la concezione platonizzante e quella aristotelica) e illustrando le diverse concezioni di fabula, fictio, allegoria e mimesis evidenzia lo sgretolarsi progressivo della nozione di fabula, a favore del manifestarsi di valori nuovi, provenienti dalla retorica, dalla filosofia e dalla teoria dell'arte, in un ripensamento della poesia nella prospettiva della teoria letteraria moderna. 